\title{
Automated Quantification of Pulmonary Perfused Blood Volume by Dual-Energy CTPA in Chronic Thromboembolic Pulmonary Hypertension
}

\section{Automatische Quantifizierung des perfundierten Lungenblutvolu- mens mittels dual-energy CTPA bei chronisch-thromboembolischer pulmonaler Hypertonie}

Authors

Affiliations
F. G. Meinel ${ }^{1}$, A. Graef ${ }^{1}$, K. M. Thierfelder ${ }^{1}$, M. Armbruster ${ }^{1}$, C. Schild ${ }^{2}$, C. Neurohr ${ }^{2}$, M. F. Reiser ${ }^{1}$, T. R. C. Johnson ${ }^{1}$

Institute for Clinical Radiology, Ludwig-Maximilians-University Hospital Munich

2 Department of Internal Medicine V, Ludwig-Maximilians-University Hospital Munich

\author{
Key words \\ - thorax \\ - vascular \\ - CT angiography \\ - CT \\ - CT-quantitative
}

received 12.1.2013

accepted $\quad 15.7 .2013$

\section{Bibliography}

DOI http://dx.doi.org/

10.1055/s-0033-1350412

Published online: 23.8.2013

Fortschr Röntgenstr 2014; 186:

151-156 @ Georg Thieme

Verlag KG Stuttgart · New York . ISSN 1438-9029

\section{Correspondence \\ Dr. Felix G. Meinel}

Institute for Clinical Radiology, Ludwig-Maximilians-University

Hospital Munich

Marchioninistr. 15

81377 Munich

Germany

Tel.: ++ 49/89/70953620

Fax: ++ 49/89/70 958832

felix.meinel@med.uni-

muenchen.de

\section{Zusammenfassung}

$\nabla$

Zielsetzung: Ziel der Studie war es zu untersuchen, ob die automatisierte Quantifizierung des perfundierten Lungenblutvolumens (PBV) in der dual-energy CT Pulmonalis-Angiografie (DECTPA) zur Beurteilung des Schweregrades einer chronisch-thromboembolischen pulmonalen Hypertonie (CTEPH) genutzt werden kann.

Methoden: Die automatisierte Quantifizierung des PBV wurde bei 25 konsekutiven Patienten mit CTEPH durchgeführt, die mittels DE-CTPA untersucht wurden. Die PBV-Werte wurden mit Parametern aus Rechtsherzkatheteruntersuchung (pulmonalarterieller Druck, Herzindex und pulmonalem Gefäßwiderstand) sowie der 6-Minuten-Gehstrecke korreliert. Hierbei wurde der Korrelationskoeffizient nach Pearson verwendet und mittels multivariater linearer Regression für Alter und Geschlecht adjustiert.

Ergebnisse: Die aus der DE-CTPA ermittelten PBVWerte korrelierten negativ mit dem systolischen $(\mathrm{r}=-0,64, \mathrm{p}=0,001)$ und mittleren $(\mathrm{r}=-0,57$, $\mathrm{p}=0,004)$ pumonalarteriellen Blutdruck. Es zeigte sich ein Trend zu einer negativen Korrelation zwischen PBV-Werten und dem pulmonalen Gefäßwiderstand $(r=-0,20, p=0,35)$. Zwischen PBV und Herzindex sowie 6-Minuten-Gehstrecke wurden keine signifikanten Korrelationen gefunden. Durch multivariate lineare Regression wurde bestätigt, dass diese Korrelationen von Alter und Geschlecht unabhänig waren.

Schlussfolgerung: Die DE-CTPA kann bei Patienten mit CTEPH für eine automatisierte Quantifizierung des perfundierten Lungenblutvolumens genutzt werden. Deren Ergebnisse korrelieren invers mit systolischem und mittlerem pulmonalarteriellen Druck und können daher den Schweregrad der pulmonalen Hypertonie bei diesen Patienten abschätzen.

\section{Abstract \\ $\nabla$}

Objectives: The aim of the study was to determine whether automated quantification of pulmonary perfused blood volume (PBV) in dual-energy computed tomography pulmonary angiography (DE-CTPA) can be used to assess the severity of chronic thromboembolic pulmonary hypertension (CTEPH).

Methods: Automated quantification of PBV was performed in 25 consecutive CTEPH patients undergoing DE-CTPA. PBV values were correlated with cardiac index and pulmonary vascular resistance quantified by right heart catheterization and walking distance in the 6-minute walk test using Pearson's correlation coefficient and multivariate linear regression analysis to control for age and gender.

Results: DE-CTPA derived PBV values inversely correlated with systolic $(r=-0.64, p=0.001)$ and mean $(\mathrm{r}=-0.57, \mathrm{p}=0.004)$ pulmonary arterial pressure. There was a trend for PBV values to inversely correlate with pulmonary vascular resistance $(r=-0.20$, $\mathrm{p}=0.35$ ). No significant correlation was found between PBV values and cardiac index or 6-minute walking distance. These correlations were confirmed to be independent of age and gender on multivariate linear regression analysis.

Conclusion: DE-CTPA can be used for an automated quantification of pulmonary PBV in chronic thromboembolic pulmonary hypertension. PBV values correlate inversely with systolic and mean pulmonary arterial pressure and can thus be used to estimate the severity of pulmonary hypertension in these patients.

Citation Format:

- Meinel FG, Graef A, Thierfelder KM etal. Automated Quantification of Pulmonary Perfused Blood Volume by Dual-Energy CTPA in Chronic Thromboembolic Pulmonary Hypertension. Fortschr Röntgenstr 2014; 186: 151-156 


\section{Introduction}

$\nabla$

Chronic thromboembolic pulmonary hypertension (CTEPH) is a persistent elevation of pulmonary arterial pressure (PAP), which develops in $2-4 \%$ of patients after acute pulmonary embolism (PE) [1 - 3]. Pathophysiologically, CTEPH is characterized by persistent vascular obstruction, small-vessel arteriopathy and vasoconstriction, all contributing to chronic elevation of the PAP [1]. Patients with CTEPH often present with progressively worsening dyspnea and exercise intolerance. The diagnosis is often suspected based on a clinical history of pulmonary embolism and/or signs of right heart dysfunction on echocardiography.

Imaging is commonly performed in CTEPH to confirm the diagnosis and exclude other causes of pulmonary hypertension, to localize the extent of disease and to determine whether a patient is a suitable candidate for pulmonary thromboendarterectomy.[1] Ventilation-perfusion (V/Q) scintigraphy typically demonstrates peripheral wedge-shaped perfusion defects without matching ventilation defects [4]. Characteristic findings of CTEPH on CT pulmonary angiography (CTPA) include mosaic attenuation pattern, dilatation of the proximal pulmonary arteries and vascular stenosis and vascular obstruction $[2,5]$. Contrast-enhanced MR angiography can also demonstrate vascular abnormalities associated with CETPH but has been shown to be inferior to CTPA in this indication [6, 7]. It has been shown that V/Q scintigraphy has a higher sensitivity and negative predictive value for CTEPH than CTPA [4]. However, V/Q scintigraphy is inferior to CTPA in assessing the exact anatomical extent of disease, in differentiating CTPEH from recurrent acute PE and in excluding abnormalities of the pulmonary parenchyma such as emphysema or interstitial lung disease as alternative causes of pulmonary hypertension. Therefore, in many centers CTEPH patients routinely undergo both V/Q scanning and CTPA. Additionally, invasive pulmonary angiography is often performed in the preoperative work-up of patients considered for pulmonary thromboendarterectomy to determine the extent of thrombotic material and assess its surgical accessibility $[1,2,8]$. In most patients with CTEPH, the diagnostic work-up is complemented by functional assessment including right heart catheterization with direct quantification of pulmonary artery pressure and other hemodynamic parameters. The six-minute walk test, quantifying the achievable walking distance, is commonly used as a measure of a patient's global functional impairment in CTEPH [9].

Among many other applications [10 - 13], dual-energy CTPA (DECTPA) can be used to generate iodine distribution maps of pulmonary parenchyma [14-16] which correspond well with pulmonary perfusion on scintigraphy [17] and SPECT [18] in acute PE. A good correlation of DE-CTPA iodine distribution maps with lung perfusion scintigraphy has been specifically demonstrated in patients with CTEPH [19]. Dual-energy CT thus simultaneously provides high-resolution morphological images of pulmonary parenchyma and functional information on pulmonary perfusion. DE-CTPA therefore represents a very promising imaging modality for patients with CTEPH since it allows simultaneous morphological assessment of pulmonary vasculature and parenchyma and functional assessment of pulmonary perfusion $[20,21]$. Therefore, the dual-energy technique is likely to increase the sensitivity of CTPA for CTEPH, although this has not yet been demonstrated conclusively.

Recently developed software allows automated quantification of pulmonary perfused blood volume (PBV) based on DE-CTPA iodine distribution maps, thus providing a quick, reader-indepen- dent tool for the assessment of global and regional pulmonary perfusion. A pilot study has found automated pulmonary PBV values to be decreased in patients with acute PE and to correlate with thrombus load [22].

The purpose of this study was to determine the diagnostic value of PBV quantification in DE-CTPA in patients with chronic thromboembolic pulmonary hypertension (CTEPH) by correlating the quantified perfused blood volume with the results of right heart catheterization and a six-minute walk test.

\section{Materials and Methods}

$\nabla$

Ethical approval and informed consent were waived by the responsible ethics committee for this retrospective analysis. All patients provided written informed consent to the CTPA examination.

\section{Patient selection}

We defined the following inclusion criteria:

1. Diagnosis of CTEPH definitely confirmed by pooled data from clinical history and examination, imaging studies (including $\mathrm{CT}$, scintigraphy or SPECT and conventional pulmonary angiography), right heart catheterization and clinical follow-up

2. Clinically indicated DE-CTPA performed

We defined the following exclusion criteria:

1. DE-CTPA with severe artifacts, inadequate vascular enhancement or timing

\section{Any cardiopulmonary comorbidities}

All DE-CTPAs performed between May 2009 and November 2011 in patients with CTEPH were assessed for any cardiopulmonary comorbidities which might influence pulmonary PBV. This was performed by an experienced chest radiologist to exclude even subtle changes such as mild emphysema or airway disease.

\section{CT image acquisition}

All DE-CTPAs were performed on a dual source CT scanner (Somatom Definition Flash, Siemens Medical, Forchheim, Germany). $85 \mathrm{~mL}$ of contrast material (Iopromide, Ultravist 370, Bayer Healthcare, Berlin, Germany) were administered via an antecubital vein at a flow rate of $5 \mathrm{~mL} / \mathrm{s}$, followed by $50 \mathrm{~mL}$ of saline, injected at the same flow rate. Scans were started using a bolus-tracking technique with a threshold of $100 \mathrm{HU}$ in the pulmonary trunk and an additional delay of $7 \mathrm{~s}$. To reduce streak artifacts caused by dense contrast material in the superior vena cava, scans were performed in a caudocranial direction. A combination of a tin-filtered (Sn) $140 \mathrm{kVp}$ and a $100 \mathrm{kVp}$ spectrum was used. Collimation was set to $32 \times 0.6 \mathrm{~mm}$. Pitch was 0.5 at a rotation time of $0.28 \mathrm{~s} /$ rot. The mean CTDI and DLP were $9.1 \pm 3.0 \mathrm{mGy}$ and 291 $\pm 91 \mathrm{mGy} \times \mathrm{cm}$, corresponding to an effective radiation dose of $4.2 \pm 1.3 \mathrm{mSv}$ (using a standard conversion factor for chest CT of $0.0145 \mathrm{mSv} / \mathrm{mGy} \times \mathrm{cm}(23))$.

\section{CT image reconstruction}

$\nabla$

CTPA images were reconstructed in axial orientation using a specific medium soft convolution kernel optimized for DE images (D30) at a $1.5-\mathrm{mm}$ slice thickness with a $1-\mathrm{mm}$ increment. To obtain axial images similar to standard $120-\mathrm{kVp}$ reconstructions with low image noise, average images were generated with equal contributions from the $\mathrm{Sn} 140 \mathrm{kVp}$ and the $100 \mathrm{kVp}$ dataset. DECT imaging allows for material differentiation based on the different 
absorption characteristics of different types of tissue. Iodine is known to produce a higher attenuation at lower tube voltage settings [24]. Thus, the spectral information obtained at different voltage settings allows for a three-material decomposition differentiating soft tissue, air, and iodine. This algorithm assigns a ratio of air and soft tissue to each voxel and uses $\mathrm{CT}$ attenuation values at both energies to derive the additional iodine content [16]. Color-coded iodine distribution maps were generated by specific, FDA-approved DE post-processing software (DE lung PBV, Siemens Healthcare) on a dedicated post-processing workstation (syngo MMWP, Somaris Version CT2008G, Siemens Healthcare). Iodine distribution ("PBV") maps were superimposed onto CTPA images at a slice thickness of $3 \mathrm{~mm}$ with a 1 -mm increment in axial, sagittal and coronal orientations.

\section{Image quality control}

To ensure valid assessment of pulmonary PBV, we excluded all examinations with severe artifacts, inadequate enhancement of the pulmonary vasculature and/or inadequate timing. For this purpose, all images considered for the study were reviewed. The degree of artifacts in iodine distribution maps (from cardiac motion, breathing or concentrated contrast material) was visually rated on a 4 -point scale $(0=$ no artifacts, $1=$ mild artifacts, $2=$ moderate artifacts, 3 = severe artifacts). Rating was performed by two radiologists in consensus. Rating was performed for upper, middle and lower lung zones. The zone with the worst rating determined the overall rating for the examination. All studies with severe artifacts were excluded from the study. Additionally, we measured enhancement in the pulmonary trunk and ascending aorta. Since lung PBV values are quantified by measuring the enhancement of the pulmonary parenchyma relative to the enhancement of the pulmonary trunk, PBV values may become unreliable with inadequate enhancement of the pulmonary vasculature and inadequate timing of the examination relative to the contrast bolus. Therefore, all examinations with enhancement of the pulmonary trunk of $<200 \mathrm{HU}$ were excluded. Since this study was performed on a second-generation dual-source scanner with an extended field of view of $32 \mathrm{~cm}$ for dual-energy applications, the dual-energy analysis fully covered the pulmonary parenchyma in all patients.

\section{CT data analysis \\ $\nabla$}

Automated quantification of pulmonary PBV was performed using the DE lung PBV application of the Syngo Dual Energy software (Siemens Healthcare, version VE32B). This analysis quantifies pulmonary PBV by measuring the enhancement of the pulmonary parenchyma in relation to the enhancement of a reference vessel. The reference vessel was defined by placing a standardized region of interest (ROI) sized $0.5 \mathrm{~cm}^{2}$ in the pulmonary trunk on axial images. The software calculates pulmonary PBV as (mean enhancement of the pulmonary parenchyma in $\mathrm{HU} /$ mean enhancement of the pulmonary trunk in HU)/calibration factor 0.15 . For example, for a vascular enhancement of 400 $\mathrm{HU}$, a mean enhancement of the pulmonary parenchyma of 400 $\mathrm{HU}^{*} 0.15=60 \mathrm{HU}$ would represent a PBV of $100 \%$. Lung isolation, lung partitioning (in upper, middle and lower zones) and enhancement analysis are performed automatically. The software then displays PBV for the entire pulmonary parenchyma, right and left lungs separately as well as lower, middle and upper zones of each lung separately.

\section{Analysis of clinical data}

Chart review was performed to obtain results from right heart catheterization (systolic and mean pulmonary arterial pressure, cardiac index and pulmonary vascular resistance) and walking distance in the 6-minute walk test. The cardiac index is defined as the cardiac output (in L/min) divided by the body surface area (in $\mathrm{m} 2$ ) and is a commonly used parameter of global circulatory function. The 6-minute walk test quantifies the distance a patient can walk during a 6-minute interval and is commonly used as a measure of a patient's global functional impairment in CTEPH [9]. Only studies performed within 6 months before or after the CTPA examination were included. If multiple studies were available within this time frame, the study closest in time to the CTPA examination was chosen.

\section{Statistical analysis}

Statistical analysis was performed using Microsoft Excel for Mac 2011 (version 14.1.3) and IBM SPSS Statistics for Mac (version 20.0.0.1). Global PBV values were correlated with parameters of right heart catheterization and the 6-minute walk test using Pearson's correlation coefficient r. Multivariate linear regression analysis was performed to determine whether possible correlations of global PBV values with parameters of right heart catheterization and the 6-minute walk test were independent of age and gender. A two-sided p-value of $<0.05$ was considered to indicate statistical significance.

\section{Results}

\section{Patient selection and characteristics}

32 patients with a definite diagnosis of chronic thromboembolic pulmonary hypertension (CTEPH) underwent DE-CTPA at our institution between May 2009 and November 2011. Four patients were excluded because of thoracic comorbidities that could potentially confound pulmonary perfusion, including pneumonia $(n=2)$ and large pleural effusions $(n=2)$. Two patients were excluded because iodine distribution maps showed severe artifacts from concentrated contrast material. One patient was excluded because of inadequate contrast timing with inadequate enhance-

Table 1 Patient characteristics.

\begin{tabular}{|c|c|c|}
\hline number of patients & \multicolumn{2}{|l|}{25} \\
\hline clinical diagnosis & \multicolumn{2}{|c|}{$\begin{array}{l}\text { chronic thromboembolic pulmonary } \\
\text { hypertension (CTEPH) }\end{array}$} \\
\hline cardiopulmonary comorbidities & \multicolumn{2}{|c|}{ none } \\
\hline \% females & \multicolumn{2}{|c|}{$52 \%(n=13)$} \\
\hline median age (range) & \multicolumn{2}{|c|}{$65(25-83)$ years } \\
\hline prior therapy & \multicolumn{2}{|c|}{$\begin{array}{l}\text { treatment naïve }(n=10) \\
\text { phosphodiesterase } 5 \text { inhibitors }(n=12) \\
\text { calcium channel blockers }(n=2) \text {, } \\
\text { endothelin receptor antagonist }(n=1)\end{array}$} \\
\hline & median & range \\
\hline pulmonary PBV (\%) & 42 & $31-67$ \\
\hline $\operatorname{PAP}_{\text {sys }}(\mathrm{mmHg})$ & 79 & $54-109$ \\
\hline $\mathrm{PAP}_{\mathrm{m}}(\mathrm{mmHg})$ & 45 & $34-66$ \\
\hline cardiac index $\left(\mathrm{L} / \mathrm{min} / \mathrm{m}^{2}\right)$ & 2.2 & $1.5-3.6$ \\
\hline $\begin{array}{l}\text { pulmonary vascular resistance } \\
(\mathrm{mmHg} / \mathrm{L} / \mathrm{min})\end{array}$ & 8.9 & $4.2-15.9$ \\
\hline 6-minute walking distance $(\mathrm{m})$ & 330 & $100-510$ \\
\hline
\end{tabular}




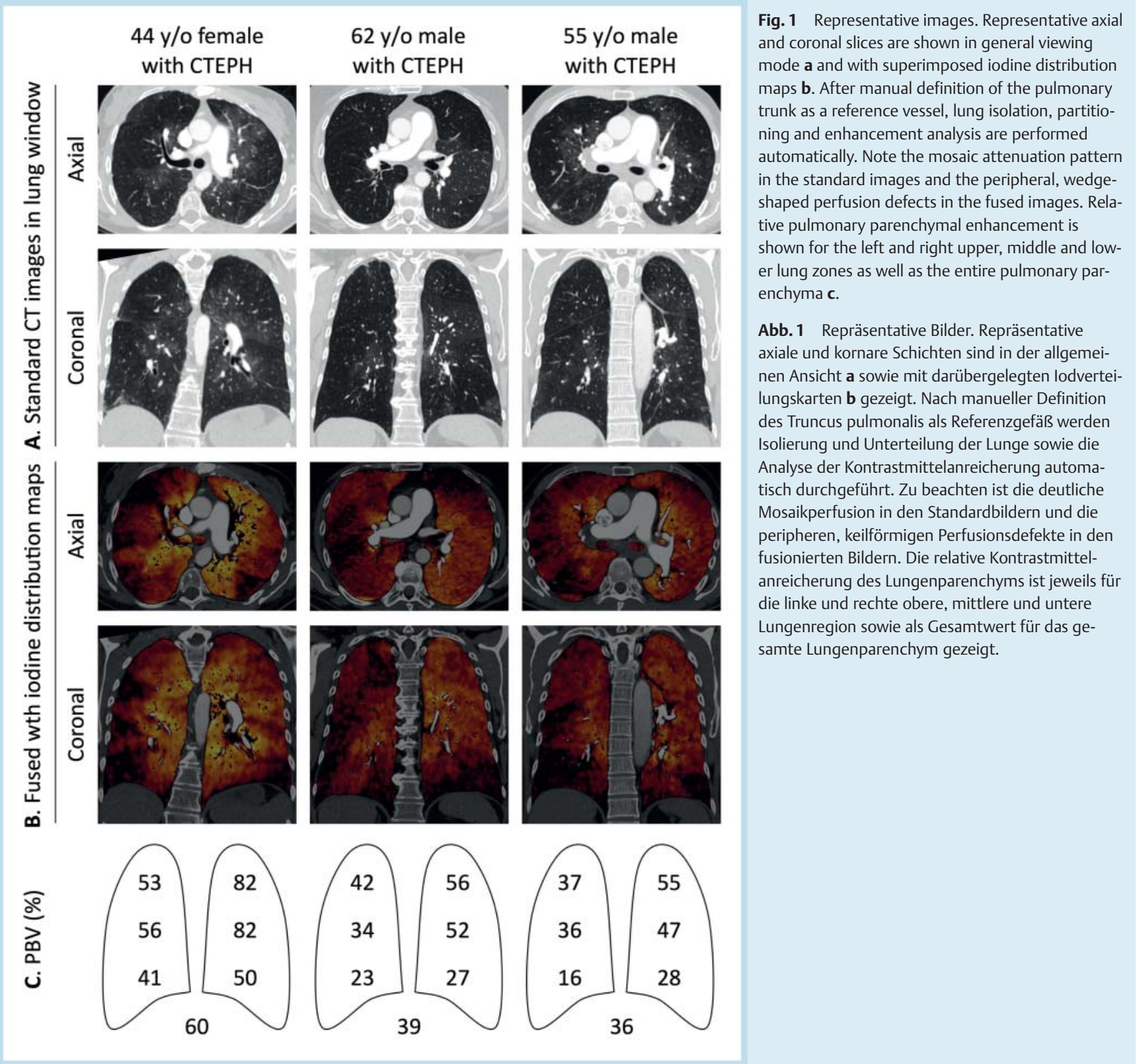

ment of the pulmonary trunk ( $<200 \mathrm{HU}$ ). The remaining 25 patients met all eligibility criteria and were included in this retrospective analysis. The patient population thus consisted of 25 patients with chronic-thromboembolic pulmonary hypertension (CTEPH) and no cardiopulmonary comorbidities. The median age was 65 years with a range of 25 - 83 years ( $\bullet$ Table 1 ). 24/25 patients had right heart catheterization and 20/25 patients had undergone the 6-minute walk test within 6 months of the CTPA examination. Representative CTPA images are shown in $\bullet$ Fig. 1. Of the examinations included in the study, 2 were rated to have no artifacts in the dual-energy iodine distribution maps, 20 were rated to display mild artifacts and 3 were rated to have moderate artifacts.

\section{Bivariate correlation of pulmonary PBV with parameters} of CTEPH severity

A highly significant negative correlation was found between pulmonary PBV values and both systolic $(r=-0.64, p=0.001)$ and mean $(\mathrm{r}=-0.57, \mathrm{p}=0.004)$ pulmonary arterial pressure ( $\bullet$ Table 2 ,
Table 2 Bivariate correlation of pulmonary PBV values with markers of CTEPH severity

\begin{tabular}{|c|c|c|}
\hline & $\begin{array}{l}\text { Pearson's correlation } \\
\text { coefficient r }\end{array}$ & p-value \\
\hline \multicolumn{3}{|l|}{ right heart catheterization } \\
\hline $\mathrm{PAP}_{\text {sys }}$ & -0.64 & 0.001 \\
\hline $\mathrm{PAP}_{\mathrm{m}}$ & -0.57 & 0.004 \\
\hline cardiac index & -0.11 & 0.62 \\
\hline pulmonary vascular resistance & -0.20 & 0.35 \\
\hline \multicolumn{3}{|l|}{ 6-minute walk test } \\
\hline 6-minute walking distance & 0.13 & 0.59 \\
\hline
\end{tabular}

- Fig. 2). There was a trend for PBV values to inversely correlate with pulmonary vascular resistance $(r=-0.20, p=0.35)$. No significant correlation was found between PBV values and cardiac in- 


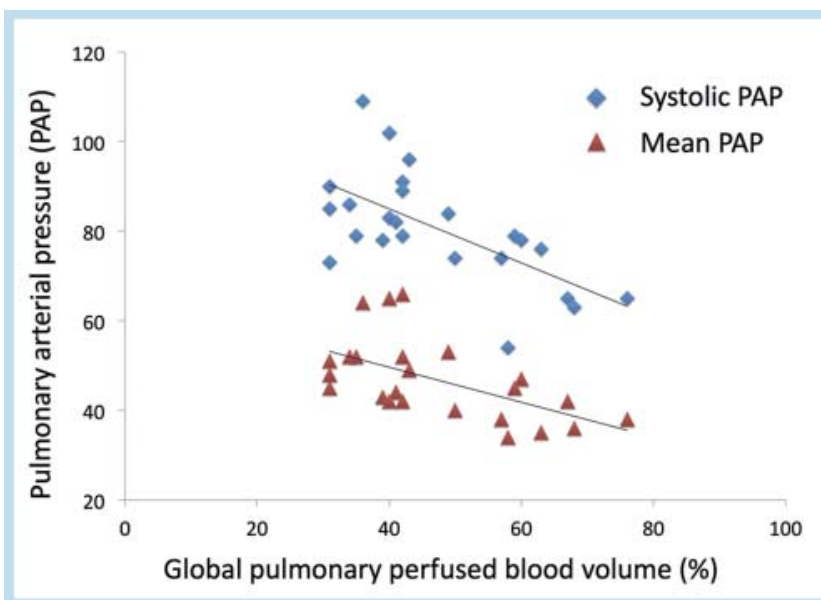

Fig. 2 Correlation of pulmonary PBV with systolic and mean pulmonary arterial pressure. Global pulmonary PBV values are plotted against the systolic and mean pulmonary arterial pressure for all patients with right heart catheterization performed within 6 months before or after the CTPA examination $(n=24)$.

Abb. 2 Korrelation des pulmonalen PBV mit systolischem und mittlerem pulmonalarteriellen Druck. Die globalen pulmonalen PBV-Werte sind gegen den systolischen und mittleren pulmonalarteriellen Druck aufgetragen. Hierbei wurden alle Patienten berücksichtigt, bei denen innerhalb von 6 Monaten vor oder nach der CTPA eine Rechtsherzkatheteruntersuchung durchgeführt wurde.

Table 3 Multivariate linear regression analysis adjusted for age and gender: correlation of pulmonary PBV values with markers of CTEPH severity.

\begin{tabular}{|lll|}
\hline & $\begin{array}{l}\text { standardized regression } \\
\text { coefficient } \boldsymbol{\beta}\end{array}$ & p-value \\
\hline right heart catheterization & & \\
\hline PAP $_{\text {sys }}$ & -0.66 & 0.001 \\
\hline PAP $_{m}$ & -0.61 & 0.003 \\
\hline cardiac index & -0.04 & 0.85 \\
\hline pulmonary vascular resistance & -0.29 & 0.17 \\
\hline 6-minute walk test & & \\
\hline 6-minute walking distance & 0.08 & 0.74 \\
\hline
\end{tabular}

dex $(r=-0.11, p=0.62)$ or 6 -minute walking distance $(r=0.13$, $\mathrm{p}=0.59)$.

\section{Covariance of pulmonary PBV with parameters of CTEPH} severity on multivariate regression analysis controlling for age and gender

These correlations were confirmed to be independent of age and gender on multivariate linear regression analysis. Again, a highly significant negative covariance was found between pulmonary PBV values and both systolic $(\beta=-0.66, p=0.001)$ and mean $(\beta=-0.61, p=0.003)$ pulmonary arterial pressure ( 0 Table 3 ). There was a trend for PBV values to inversely co-variate with pulmonary vascular resistance $(\beta=-0.29, p=0.17)$. No significant covariance was found between PBV values and cardiac index $(\beta=-0.04, p=0.85)$ or 6 -minute walking distance $(\beta=0.08$, $\mathrm{p}=0.74)$.

\section{Discussion}

This study assessed whether a quantitative analysis of the iodine distribution maps generated by dual-energy CT can be used to estimate the severity of CTEPH. Data from 25 patients with a definite diagnosis of CETPH and no cardiopulmonary comorbidities were analyzed. We found that global pulmonary perfused blood volume inversely correlates with both systolic and mean pulmonary arterial pressure. There was a trend for PBV values to inversely correlate with pulmonary vascular resistance, but no significant correlation was found between PBV values and cardiac index or 6-minute walking distance.

Our findings go beyond the data published in the literature. Renard and colleagues correlated perfusion defects on iodine distribution maps in 17 CTEPH patients with vascular changes suggestive for CTEPH including stenosis, obstruction by thrombi, webs and bands, and abrupt vessel narrowing [20]. They found that the most severe vascular changes of CTEPH were seen with a higher frequency in segments with perfusion defects on iodine distribution maps [20]. This provided first evidence that perfusion impairment on DE-CTPA iodine perfusion maps may correlate with disease severity in patients with CTEPH, which is confirmed by our results.

The only previous study to correlate DE-CTPA iodine distribution maps with clinical parameters of CTEPH severity is a study performed by Hoey and colleagues in 20 patients with CTEPH [21]. In this study, a visual score of perfusion impairment on iodine distribution maps correlated well with the extent of mosaic attenuation pattern on CT [21]. However, the visual perfusion impairment score showed no significant correlation with the degree of vascular obstruction, mean pulmonary artery pressure, or pulmonary vascular resistance [21]. This partly conflicts with our data, since we found a significant negative correlation between global PBV and pulmonary artery pressure. The reason for this disagreement may be imperfections in the visual scoring of perfusion defects on iodine distribution maps. In the technique we propose, quantification of PBV is performed automatically after manual definition of the pulmonary trunk, thus rendering PBV values rater-independent. Furthermore, automated quantification of pulmonary PBV is much faster than visual scoring of perfusion defects on iodine distribution maps, making it much more suitable for an application in routine clinical diagnostic work-up. On the other hand, visual assessment of iodine distribution may be more accurate in the differentiation of pseudodefects from real perfusion defects than in the automated quantification of pulmonary PBV. However, visual assessment of iodine distribution maps is reader-dependent and more time-consuming.

It is known from MR lung perfusion studies that pulmonary blood flow is doubled in expiration compared to inspiration [25]. This is largely because the ratio of air to tissue per volume is decreased, thus increasing perfusion per volume [26]. Even though all our scans were performed in full inspiration, differences in inspirational effort may account for some of the inter-individual differences in our study, possibly explaining the only moderate correlations with disease severity.

Since there are considerable inter-individual variations in PBV even in the absence of pathology, it is reasonable to hypothesize that the correlation between PBV values and pulmonary arterial pressure may be even stronger for examinations of the same CTEPH patient at different time points. Therefore, DE-CTPA with automated quantification of pulmonary PBV may represent a non-invasive alternative to right heart catheterization for evalu- 
ating disease progression, assessing the response to medical therapy or monitoring patients after pulmonary thromboendarterectomy. DE-CTPA lacks the risks associated with the invasive procedure at the expense of exposing the patient to ionizing radiation. The radiation dose associated with DE-CTPA does not exceed the dose of a conventional, single-spectrum CTPA examination [27]. Compared to the average effective radiation dose of $1.4 \mathrm{mSv}$ for combined ventilation/perfusion scintigraphy [28], the radiation dose of one DE-CTPA examination - approximately $4 \mathrm{mSv}$ in our study - is higher by a factor of 3 . The incremental life-time risk of malignancy associated with this radiation dose is of only marginal significance compared to the high morbidity and mortality of patients with CTEPH. Nevertheless, the radiation exposure associated with DE-CTPA represents a limitation in patients who require frequent follow-up examinations.

The results of this study have to be seen in light of the study design. First, in order to avoid confounding of PBV values, we excluded CTEPH patients with cardiopulmonary comorbidities. The influence of these comorbidities on DE-CTPA pulmonary PBV values in an unselected patient population needs to be addressed in further studies. However, only four patients were excluded from our study because of comorbidities including large pleural effusions and pneumonia. Therefore, the technique presented here is applicable in the majority of CTEPH patients. Second, the majority of patients in our study had - although mostly mild - artifacts in the dual-energy iodine distribution maps. We cannot exclude that subtle pseudoperfusion defects caused by cardiac pulsation or breathing artifacts may have influenced PBV values. Third, limited statistical power may be one reason why we did not find significant correlations between PBV and some clinical parameters of disease severity. This is particularly true for pulmonary vascular resistance where there was at least a trend towards an inverse correlation. Fourth, this was a retrospective study in a relatively small number of patients. Before the technique can be incorporated into the clinical routine, the results should be confirmed in larger, prospective trials.

In conclusion, automated quantification of pulmonary PBV in DECTPA provides an immediate, reader-independent estimation of global pulmonary perfusion in chronic thromboembolic pulmonary hypertension, which correlates inversely with systolic and mean pulmonary arterial pressure and can thus be used to estimate the severity of pulmonary hypertension in these patients.

\section{References}

1 Piazza G, Goldhaber SZ. Chronic thromboembolic pulmonary hypertension. N Engl J Med [Review] 2011; 4 (364): 351 - 360

2 Jenkins $D$, Mayer E, Screaton $N$ et al. State-of-the-art chronic thromboembolic pulmonary hypertension diagnosis and management. Eur Respir Rev [Case Reports Research Support, Non-U.S. Gov't Review] 2012; 123: 32-39

3 Lang IM, Klepetko W. Chronic thromboembolic pulmonary hypertension: an updated review. Curr Opin Cardiol [Research Support, NonU.S. Gov't Review] 2008; 6: 555-559

4 Tunariu N, Gibbs SJ, Win Z et al. Ventilation-perfusion scintigraphy is more sensitive than multidetector CTPA in detecting chronic thromboembolic pulmonary disease as a treatable cause of pulmonary hypertension. J Nucl Med [Comparative Study Evaluation Studies] 2007; 5: $680-684$

5 Willemink MJ, van Es HW, Koobs L et al. CT evaluation of chronic thromboembolic pulmonary hypertension. Clin Radiol [Review] 2012; 67: $277-285$

6 Kreitner KF, Kunz RP, Ley S et al. Chronic thromboembolic pulmonary hypertension - assessment by magnetic resonance imaging. Eur Radiol [Review] 2007; 17: 11-21
7 Ley S, Ley-Zaporozhan J, Pitton MB et al. Diagnostic performance of state-of-the-art imaging techniques for morphological assessment of vascular abnormalities in patients with chronic thromboembolic pulmonary hypertension (CTEPH). Eur Radiol [Research Support, Non-U. S. Gov't] 2012; 22: 607-616

8 Keogh AM, Mayer E, Benza RL et al. Interventional and surgical modalities of treatment in pulmonary hypertension. J Am Coll Cardiol [Review] 2009, (Suppl 1): S67-S77

9 Reesink HJ, van der Plas MN, Verhey NE et al. Six-minute walk distance as parameter of functional outcome after pulmonary endarterectomy for chronic thromboembolic pulmonary hypertension. J Thorac Cardiovasc Surg. [Research Support, Non-U. S. Gov't]. 2007; 133: $510-$ 516

10 Korkusuz H, Abbas RaschidiB, Keese D et al. Diagnosing and quantification of acute alcohol intoxication-comparison of dual-energy CT with biochemical analysis: initial experience. Fortschr Röntgenstr [Comparative Study] 2012; 184: 1126-1130

11 Bragelmann A, Bunck A, Donas K et al. Dual-Energy CT in the Follow-Up after Endovascular Abdominal Aortic Aneurysm Repair. Fortschr Röntgenstr 2013

12 Lu GM, Zhao Y, Zhang LJ et al. Dual-energy CT of the lung. Am J Roentgenol Am J Roentgenol. [Research Support, Non-U.S. Gov't Review] 2012; 199: S40 -S53

13 De Cecco CN, Darnell A, Rengo M et al. Dual-energy CT: oncologic applications. Am J Roentgenol Am J Roentgenol [Review]. 2012; 199: S98S105

14 Wu AS, Pezzullo JA, Cronan JJ et al. CT pulmonary angiography: quantification of pulmonary embolus as a predictor of patient outcome-initial experience. Radiology 2004; 230: 831 - 835

15 Thieme SF, Johnson TR, Lee C et al. Dual-energy CT for the assessment of contrast material distribution in the pulmonary parenchyma. Am J Roentgenol Am J Roentgenol 2009; 193: 144-149

16 Johnson TR, Krauss B, Sedlmair M et al. Material differentiation by dual energy CT: initial experience. Eur Radiol 2007; 17: 1510-1517

17 Thieme SF, Becker CR, Hacker M et al. Dual energy CT for the assessment of lung perfusion-correlation to scintigraphy. Eur J Radiol [Comparative Study Evaluation Studies] 2008; 68: 369-374

18 Thieme SF, Graute V, Nikolaou K et al. Dual Energy CT lung perfusion imaging-correlation with SPECT/CT. Eur J Radiol 2012; 81: 360 - 365

19 Nakazawa $T$, Watanabe $Y$, Hori $Y$ et al. Lung perfused blood volume images with dual-energy computed tomography for chronic thromboembolic pulmonary hypertension: correlation to scintigraphy with single-photon emission computed tomography. J Comput Assist Tomogr [Comparative Study]. 2011; 35: 590-595

20 Renard B, Remy-Jardin M, Santangelo T et al. Dual-energy CT angiography of chronic thromboembolic disease: can it help recognize links between the severity of pulmonary arterial obstruction and perfusion defects? Eur J Radiol 2011; 79: 467 - 472

21 Hoey ET, Mirsadraee S, Pepke-Zaba J et al. Dual-energy CT angiography for assessment of regional pulmonary perfusion in patients with chronic thromboembolic pulmonary hypertension: initial experience. Am J Roentgenol Am J Roentgenol [Research Support, Non-U. S. Gov't]. 2011; 196: 524-532

22 Sueyoshi E, Tsutsui S, Hayashida Tet al. Quantification of lung perfusion blood volume (lung PBV) by dual-energy CT in patients with and without pulmonary embolism: preliminary results. Eur J Radiol 2011; 80: e505-e509

23 Deak PD, Smal Y, Kalender WA. Multisection CT protocols: sex- and age-specific conversion factors used to determine effective dose from dose-length product. Radiology [Research Support, Non-U.S. Gov't] 2010; $257: 158-166$

24 Nikolaou K, Thieme S, Sommer $W$ et al. Diagnosing pulmonary embolism: new computed tomography applications. J Thorac Imaging [Review] 2010; 25: 151-160

25 Cao JJ, Wang Y, Schapiro W et al. Effects of respiratory cycle and body position on quantitative pulmonary perfusion by MRI. J Magn Reson Imaging 2011; 34: 225-230

26 Hopkins SR, Wielputz MO, Kauczor HU. Imaging lung perfusion. J Appl Physiol 2012; 113: 328-339

27 Schenzle JC, Sommer WH, Neumaier K et al. Dual energy CT of the chest: how about the dose? Invest Radiol 2010; 45: 347-353

28 Groves AM, Yates SJ, Win T et al. CT pulmonary angiography versus ventilation-perfusion scintigraphy in pregnancy: implications from a UK survey of doctors' knowledge of radiation exposure. Radiology [Comparative Study] 2006; 240: 765 -770 